\section{Fruitless Ruellia simplex R12-2-1 (Mayan Compact Purple)}

\author{
Rosanna Freyre ${ }^{1}$
}

Environmental Horticulture Department, Institute of Food and Agricultural Sciences, University of Florida, P.O. Box 110670, Gainesville, FL 32611

\section{Zhanao Deng}

Environmental Horticulture Department, Gulf Coast Research and Education Center, Institute of Food and Agricultural Sciences, University of Florida, 14625 County Road 672, Wimauma FL 33598

\section{Gary W. Knox}

Environmental Horticulture Department, North Florida Research and Education Center, Institute of Food and Agricultural Sciences, University of Florida, 155 Research Road, Quincy, FL 32351

\section{Steven Montalvo}

Environmental Horticulture Department, Institute of Food and Agricultural Sciences, University of Florida, P.O. Box 110670, Gainesville, FL 32611

\section{Victor Zayas}

Environmental Horticulture Department, Institute of Food and Agricultural Sciences, University of Florida, P.O. Box 110670, Gainesville, FL 32611

Additional index words. Acanthaceae, hybridization, invasive plants, mexican petunia, plant breeding, polyploidization, sterility

Ruellia $\mathrm{L}$. is the second largest genus in the Acanthaceae and consists of $\approx 300$ species of perennial herbs, shrubs, small trees, and lianas with tropical, subtropical, or temperate distribution (Tripp, 2007). Ruellia simplex Wright (commonly known as mexican petunia, mexican bluebell, or britton's petunia) has low maintenance requirements and prolific flowering, and has become a very popular landscape plant in the southern United States (Gilman, 1999) since its introduction to Florida sometime before 1940 (Hupp et al., 2009).

Ruellia simplex has naturalized in disturbed uplands and wetlands of seven southern U.S. states (from Florida and South Carolina, west to Texas), plus the U.S. Virgin Islands, Puerto Rico, and Hawaii (USDA, 2012). Since 2001, the Florida Exotic Pest Plant Council has considered mexican petunia as a Category I invasive plant, described as "plants that are altering native plant communities

Received for publication 4 May 2016. Accepted for publication 6 Sept. 2016.

The development and evaluation of Ruellia was funded in part, by the USDA/Tropical and Subtropical Agriculture Research (TSTAR) program and the Florida Nursery, Growers and Landscape Association.

We thank Gail Bowman, Allison Conner, Mark Kann, Adam Moseley, Brian Owens, and Charles B. Riddle for their technical assistance, and Jingsheng Huang for help with statistical analyses.

${ }^{1}$ Corresponding author. E-mail: rfreyre@ufl.edu. by displacing native species, changing community structures or ecological functions, or hybridizing with natives" (FLEPPC, 2015). The University of Florida Institute for Food and Agricultural Science (UF/IFAS) Assessment of the Status of Non-Native Plants in Florida's Natural Areas also considers $R$. simplex as an invasive (D) taken on 9 Sept. 2015 (week 17) at Citra, FL. species, and does not recommend its use in Florida (IFAS, 2015).

A survey conducted in 2002 including 946 active nurseries in Florida indicated that $15.9 \%$ of them grew or sold $R$. simplex, and the total annual sales for this plant was estimated at about $\$ 12$ million (Wirth et al., 2004). Until recently, the only $R$. simplex cultivars available were tall ('Purple Showers', 'Chi Chi', and 'Snow White') and dwarf ('Katie' and 'Southern Star' series) in purple, pink, and white flower colors. These cultivars are clonally propagated, except for the 'Southern Star' series which is propagated by seed (PanAmerican Seed Co., Chicago, IL). With the exception of 'Purple Showers', which does not set fruit by open pollination (Wilson and Mecca, 2003), all known cultivars set fruit and are potentially invasive.

In 2007, a Ruellia breeding program was initiated at UF/IFAS in Gainesville, FL, directed specifically toward creating new highly infertile cultivars for the landscape plant industry. To reduce the spread of $R$. simplex by seed, cultivars with low female fertility (fruitlessness or lack of seed viability) and reduced or lack of male fertility are developed (Freyre et al., 2012a). Ruellia Mayan Purple (R10-102, PP24422) and Mayan White (R10-108, PP25156) were released in 2012 (Freyre et al., 2012b), and Mayan Pink in 2013 (R10105-Q54, PP26063) (Freyre and Wilson, 2014). These three cultivars were evaluated by the IFAS Invasive Plants Assessment and their landscape use was approved. Ruellia R12-2-1 described below was obtained by a combination of hybridization and polyploidization using oryzalin. It was selected in multilocation trials in Florida in 2015 from a group of 13 different clones and

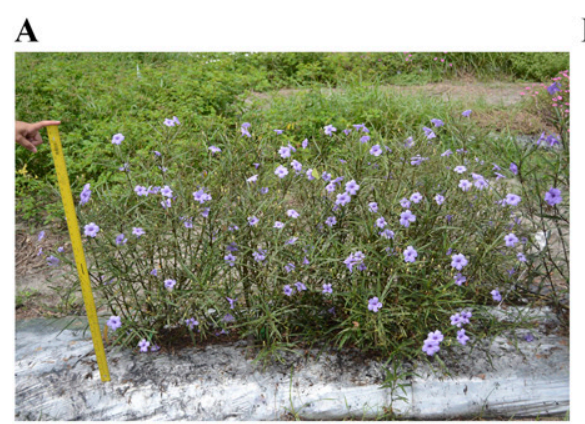

B

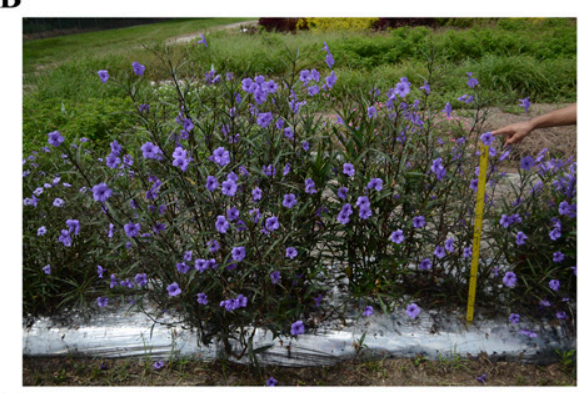

D

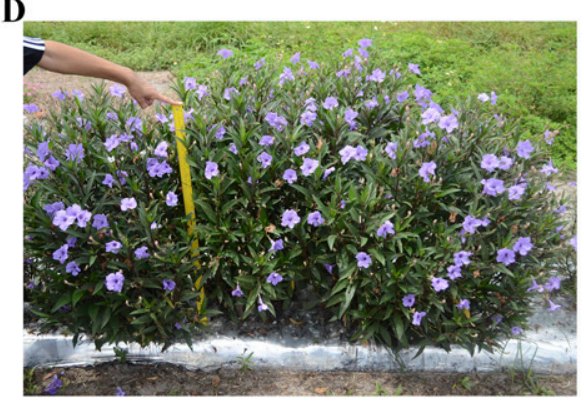

Fig. 1. Plots of three plants of wild R. simplex (A), 'Purple Showers' (B), Mayan Purple (C), and R12-2-1 
commercial cultivars due to excellent landscape performance, medium plant height, and no fruiting.

\section{Origin}

R12-2-1 is a seedling obtained at UF in Gainesville, FL, from the cross RU64 × 37-36-1 made on Feb. 2012. RU64 is a whiteflowered, tetraploid accession of $R$. simplex. 37-3-6-1 is an $F_{1}$ tetraploid plant which has a white flower with purple corolla tube obtained from selfing clone 37-3-6. Clone 37-3-6 was obtained by treating the apical meristem of a mutant of $R$. simplex with white flowers with purple corolla tube with three applications, every $12 \mathrm{~h}$, of a $50 \mu \mathrm{M}$ oryzalin solution following Jones et al. (2008). Ploidy levels were determined by flow cytometrical analysis following Arumuganathan and Earle (1991) using wild $R$. simplex (the naturalized and cultivated, nonimproved form of the species) as diploid control.

\section{Description}

To botanically characterize R12-2-1, plants were propagated by cuttings and grown in a research greenhouse in Gainesville, FL. Plants were $\approx 17$ weeks of age when flower corolla diameter was measured and descriptions of color for plant parts were determined based on comparison with the Royal Horticultural Society Color Chart (Royal Horticultural Society, 1995). Measurements for plant height and width for R12-2-1 and three controls were taken on field plants that were 21 weeks in age, on a total of 27 plants per clone or cultivar ( 3 plants $\times 3$ blocks $\times 3$ sites) grown in Florida in 2015, and then averaged. Number of stems, and length and number of nodes of the longest stem for R12-2-1, and two comparison cultivars were taken at three sites, while leaf length and width were taken at only two sites.

R12-2-1 (Fig. 1). This plant has an upright clumping, compact and vigorous growth habit. It is different from the previously released Mayan Purple in that it has a shorter height, more branching, and wider and greener leaves, which contribute toward higher landscape plant performance.

Stems in R12-2-1 are brown with a purple tint (RHS 200A) when mature. New growth is lighter in color (RHS 138B) and progressively gets darker with age. Stems are

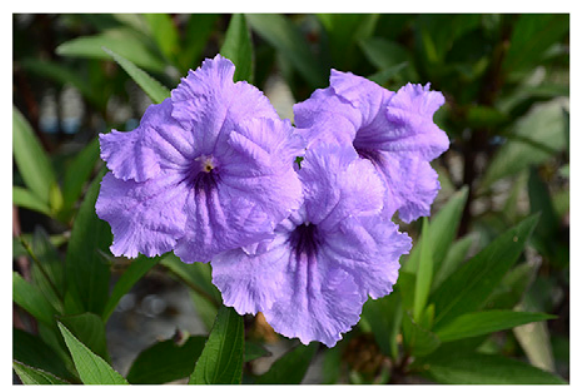

Fig. 2. Flowers on Ruellia simplex R12-2-1.

\section{A. Plant Height}

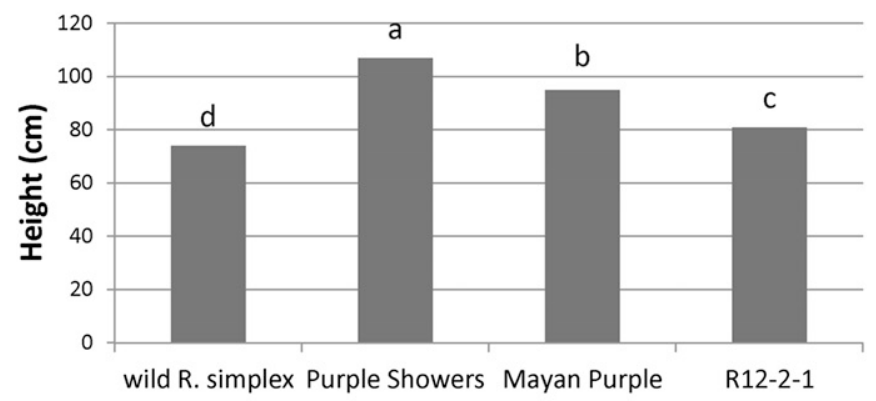

C. Number of stems per plant

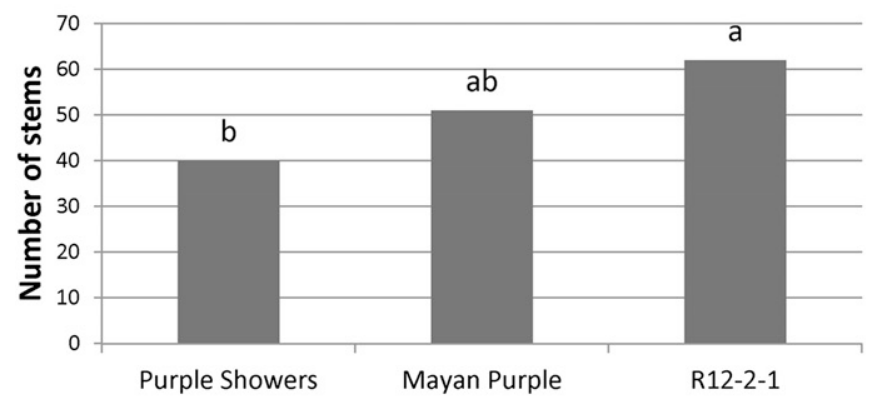

E. Number of nodes in longest stem

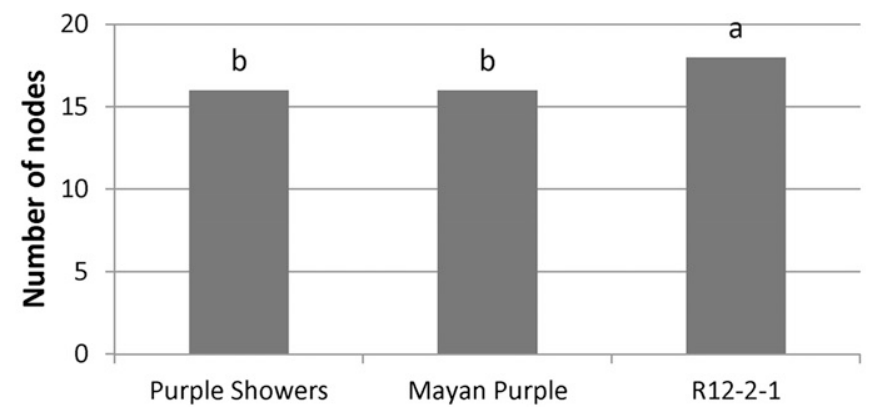

B. Plant Width

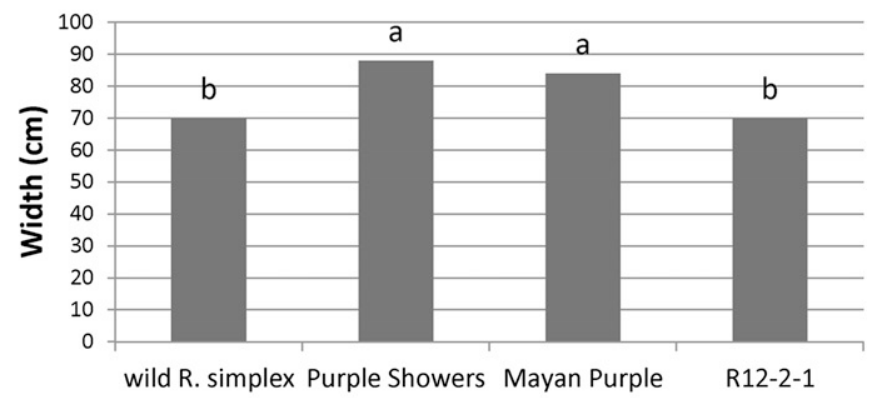

D. Length of longest stem

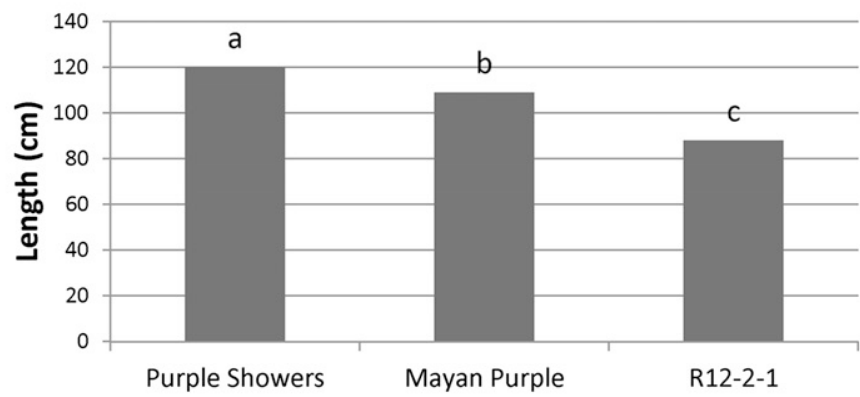

F. Leaf area

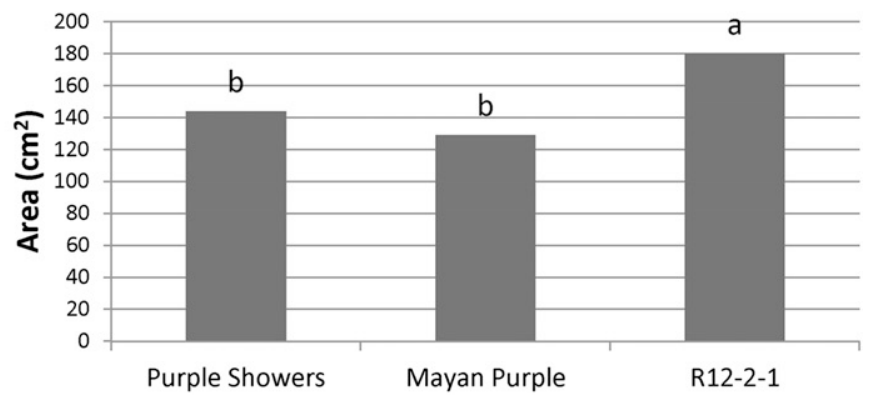

Fig. 3. (A-F). Average plant height, plant width, number of stems per plant, length of the longest stem, number of nodes in the longest stem, and leaf area at week 16, respectively, for wild Ruellia simplex, 'Purple Showers', Mayan Purple, and R12-2-1 at three locations in Florida. The same letter over a bar indicates that the values are not significantly different $(P<0.005)$. 
between round and square. Stems can become woody near the base of mature plants, and rhizomes may form where conditions are favorable and resources are not limited. Nodes can exhibit swelling and are typically brown-black (darker than RHS 200A, but lighter than 202A), but color can vary based on light exposure and fertility. The nodes and the midrib to about $1 / 4$ up the leaf on the abaxial and adaxial surfaces are slightly tomentose. The leaves are oppositely attached and are lanceolate with an entire margin, narrowly acute apex, and an attenuate base. Leaves on R12-2-1 are green on the adaxial (RHS 147A) and abaxial (RHS 137B) side of the lamina, respectively, apparently darker green than in Mayan Purple with adaxial (RHS 139A) and abaxial (RHS 137C) lamina colors, respectively; however, color can vary depending on fertility levels. Venation on the abaxial surface of the lamina in R12-2-1 has the same color as the abaxial leaf surface, is pinnate and prominently raised. Average length of mature leaves in R12-2-1 is $8.5 \mathrm{~cm}$, similar to that of Mayan Purple at $8.3 \mathrm{~cm}$, and significantly different from that of 'Purple Showers' at $9.8 \mathrm{~cm}$. The leaf width for R12-2-1 is $1.7 \mathrm{~cm}$, significantly different from that of Mayan Purple and 'Purple Showers' with 1.2 and $1.1 \mathrm{~cm}$, respectively. Using the formula for area of an ellipse, leaf area for R12-2-1 averages 180 $\mathrm{cm}^{2}$, significantly different from 'Purple Showers' and Mayan Purple with 144 and $129 \mathrm{~cm}^{2}$, respectively.

Flowers in R12-2-1 are pedunculate, complete perfect, and borne from the axil either solitarily or in a several-flowered cyme. They are actinomorphic and funnel form with five petals, four anthers, and one stigma. Glandular trichomes cover the sepal surface of unopened and open flowers. Flowers are violet (RHS 87B) with a darker violet (RHS 86A) corolla tube (Fig. 2A) and last $1 \mathrm{~d}$, after which the corolla falls. The corolla diameter (average of 20 flowers on 17-week greenhouse plants) averages $5.5 \mathrm{~cm}$, the same as in Mayan Purple, slightly smaller than those of 'Purple Showers' with $5.7 \mathrm{~cm}$, and larger than those of wild $R$. simplex with $4.7 \mathrm{~cm}$.

\section{Multilocation Replicated Evaluations of Landscape Performance, Flowering, and Fruiting}

Plants were trialed in three simultaneous field experiments conducted at Quincy (northwestern Florida, $30.5^{\circ} \mathrm{N}, 84.6^{\circ} \mathrm{W}$, AHS heat zone 9, USDA hardiness zone 8b), Citra (north central Florida, $29.4^{\circ} \mathrm{N}$, $82.2^{\circ} \mathrm{W}$, AHS heat zone 10, USDA hardiness zone 9a), and Wimauma (southwest Florida, $27.45^{\circ} \mathrm{N}, 82.1^{\circ} \mathrm{W}$, AHS heat zone 10, USDA hardiness zone 9b) (American Horticultural Society, 2015; USDA, 2012). The experimental design was a randomized complete block with three blocks. Each plot consisted of three plants for each clone, spaced $50 \mathrm{~cm}$ apart. At each experimental site, wild $R$. simplex (diploid), 'Purple Showers', and Mayan Purple (tetraploids) were included as purple-flowered controls and compared with R12-2-1.

Details on field trials have been described elsewhere (Freyre et al., 2012a). Briefly, 27 cuttings for each plant were clonally propagated, rooted in 2 weeks, and then transplanted into 10-cm Ellepots (Blackmore Co. Inc., Belleville, MI). They were moved to an open-sided greenhouse for hardening for 3 weeks, during which they were fertilized with $150 \mathrm{ppm} N$ with Peters liquid fertilizer at each irrigation $(20 \mathrm{~N}-4.4 \mathrm{P}-166 \mathrm{~K}$; Everris, Charleston, SC). When plants were 5 weeks old, they were distributed to each site and then transplanted to ground beds in full sun within a week. At each site, rows were
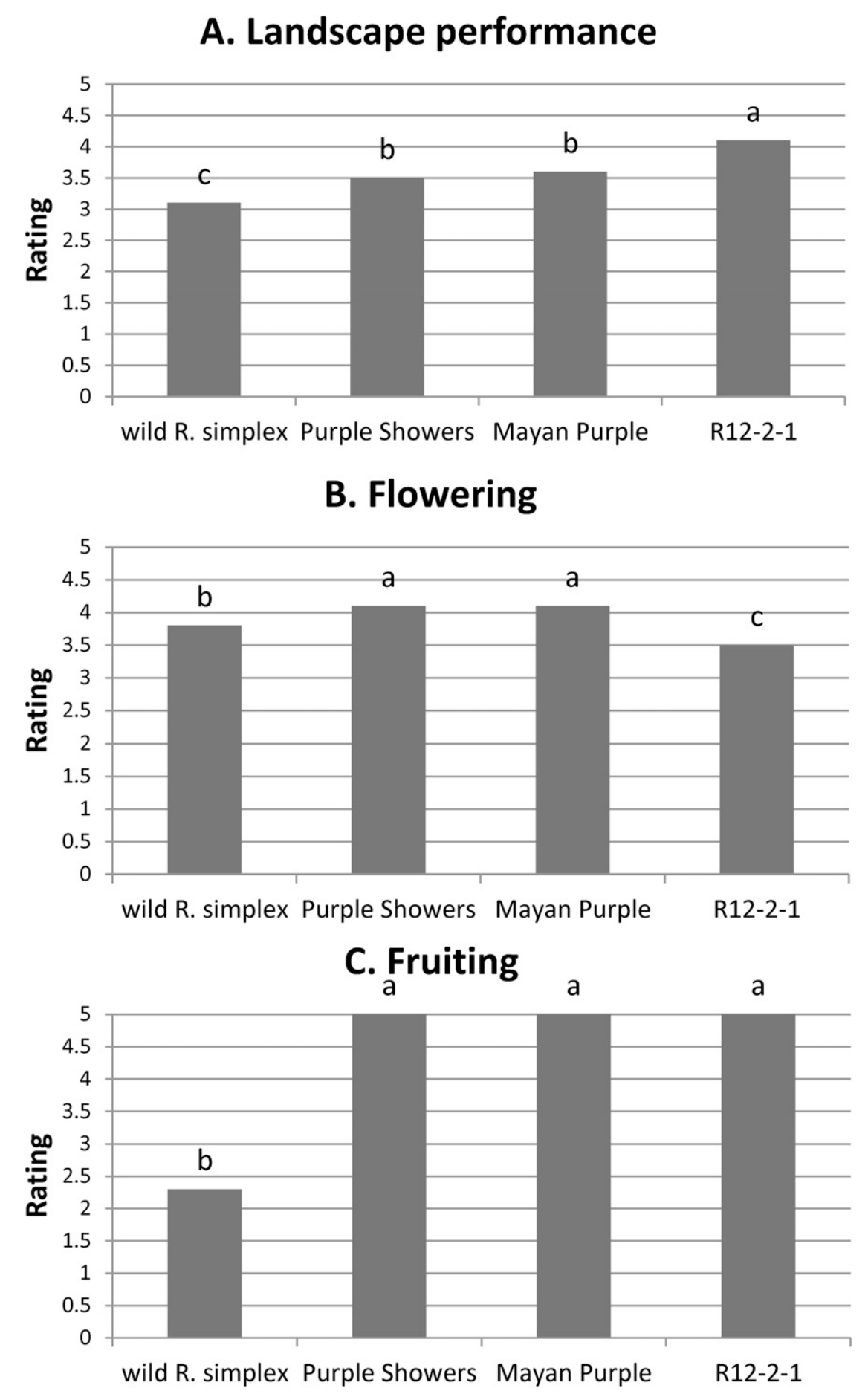

Fig. 4. (A) Average landscape performance rating over 16 weeks for wild Ruellia simplex, 'Purple Showers', Mayan Purple, and R12-2-1 at three locations in Florida. Ratings range from 1 = poor landscape performance to $5=$ excellent landscape performance. (B) Average flowering rating over 16 weeks for wild $R$. simplex, 'Purple Showers', Mayan Purple, and R12-2-1 at three locations in Florida. Ratings range from $1=$ no flowers to $5=$ more than 20 flowers. (C) Average fruiting rating over 16 weeks for wild $R$. simplex, 'Purple Showers', Mayan Purple, and R12-2-1 at three locations in Florida. Ratings range from $1=$ more than 50 fruits to $5=$ no fruits. 
formed and covered with plastic. In Quincy, white plastic was used (Raven Industries, Sioux Falls, SD), whereas in Citra, it was silver, and in Wimauma, it was white over black (both from Berry Plastics Corp., Sarasota, FL). Transplanting was completed between 11 and 15 May 2015. Within $3 \mathrm{~d}$ after transplanting, each plant was top dressed with $\approx 15 \mathrm{~g}$ of the controlled-release fertilizer Osmocote $^{\circledR} \quad(15 \mathrm{~N}-39.6 \mathrm{P}-99.6 \mathrm{~K}$, 4-6 months; Everris $\left.{ }^{\mathrm{TM}}\right)$. Irrigation was through drip tape under the rowcovers, and was supplied as needed at each site depending on the soil type and weather conditions.

After 4 weeks from transplant, each plant was evaluated every 2 weeks until week 16 , for landscape performance with a scale from 1 to 5 , where $1=$ very poor quality, not acceptable, severe leaf necrosis or chlorosis, poor form; 2 = poor quality, not acceptable, large areas of necrosis or chlorosis, poor form; 3 = acceptable quality, somewhat desirable form and color; 4 = very good quality, very acceptable and desirable color and form; $5=$ excellent quality, perfect condition, premium color and form. In Ruellia, excellent form is considered when plants are well branched and full, do not lodge, and have stems of about uniform length. Flowering was rated on a $1-5$ scale where $1=$ no flowers or buds; 2 = buds, but no open flowers; $3=1-$ 10 open flowers; $4=11-20$ open flowers; $5=$ more than 20 open flowers. Fruiting was rated on a $1-5$ scale where $1=$ more than 50 fruits; $2=21-50$ fruits; $3=11-20$ fruits; $4=1-10$ fruits; $5=$ no fruit. On week 16, plant height and average width (average of widths taken north-south and east-west) were measured for each plant at each site. Plants that were leaning were propped up to get a full height measurement. On week 17, plants were cut at the base, bagged, and brought indoors for data collection of number of stems, and length and number of nodes on the longest stem. Data were analyzed using SAS PROC GLM with mean separation using Tukey's Studentized range test (honestly significant difference) at $P=0.005$ (SAS Institute, 2004). Photos of plants of R12-2-1 and the three controls taken at week 17 in Citra, FL, are shown (Fig. 1) as well as a close up of flowers on R12-2-1 (Fig. 2).

Vegetative measurements. For R12-2-1 and the three controls, there were significant differences $(P<0.005)$ for average plant height between sites, clones, and the interaction of site $\times$ clone, whereas the difference between blocks was not significant. For plant width, the interaction of site $\times$ clone and difference between blocks were not significant. Height was different at all locations, being higher at Wimauma (southwestern), intermediate at Quincy (northwestern), and shorter at Citra (north central). Width was higher at Quincy, and not significantly different at Wimauma and Citra. Plant height for R12-2-1 averaged over the three locations was $81 \mathrm{~cm}$, significantly different from 'Purple Showers' with $107 \mathrm{~cm}$, Mayan Purple with $95 \mathrm{~cm}$, and wild $R$. simplex with $74 \mathrm{~cm}$. Average plant width was $73 \mathrm{~cm}$, similar to wild $R$. simplex with $70 \mathrm{~cm}$, and significantly different from 'Purple Showers' and Mayan Purple with 88 and $84 \mathrm{~cm}$, respectively. Average number of stems per plant for R122-1 was 62, 51 for Mayan Purple, and significantly different for 'Purple Showers' with 40 . The length of the longest stem for R12-2-1 was $88 \mathrm{~cm}$, significantly different from Mayan Purple and 'Purple Showers' with 109 and $121 \mathrm{~cm}$, respectively. The average number of nodes on this stem for R12-2-1 was 18, significantly different from Mayan Purple and 'Purple Showers' with 16 nodes (Fig. 3A-F).

Performance. For landscape performance, there were significant differences between clones, sites, and the interaction site $\times$ clone, whereas for flowering and fruiting, there were no differences between sites. R12-2-1 had the highest landscape performance with 4.1, significantly different to Mayan Purple and 'Purple Showers' with 3.5 , and wild $R$. simplex with 3.1. Flowering was highest for Mayan Purple and 'Purple Showers' with 4.1 , significantly different from wild $R$. simplex with 3.8 and R12-2-1 with 3.6. This can be attributed to a later flowering onset for R12-2-1 (data not shown). Only wild $R$. simplex had fruits and a rating of 2.3, significantly different to the three other clones with no fruit and a rating of 5 (Fig. 4A-C).

\section{Female Fertility}

Open-pollinated seed. As previously mentioned, only wild $R$. simplex had fruits in the field, either from open pollination or selfing. Its rating was 2.3 , having on average $21-50$ fruits per plant.

Seed obtained from manual hybridizations. Female fertility of R12-2-1 was evaluated by hybridizing it with three male fertile clones: diploid wild $R$. simplex, diploid pink-flowered 'Chi Chi', and tetraploid RU64. Plants were maintained in a greenhouse at UF, Gainesville, FL. Twenty manual hybridizations for each combination were performed as previously described (Freyre et al., 2012b). None of the cross combinations were successful in forming fruit, confirming that R12-2-1 is highly female infertile.

\section{Male Fertility and Pollen Stainability}

Seed obtained from manual hybridizations. Male fertility of R12-2-1 was evaluated by hybridizing it with three female fertile clones

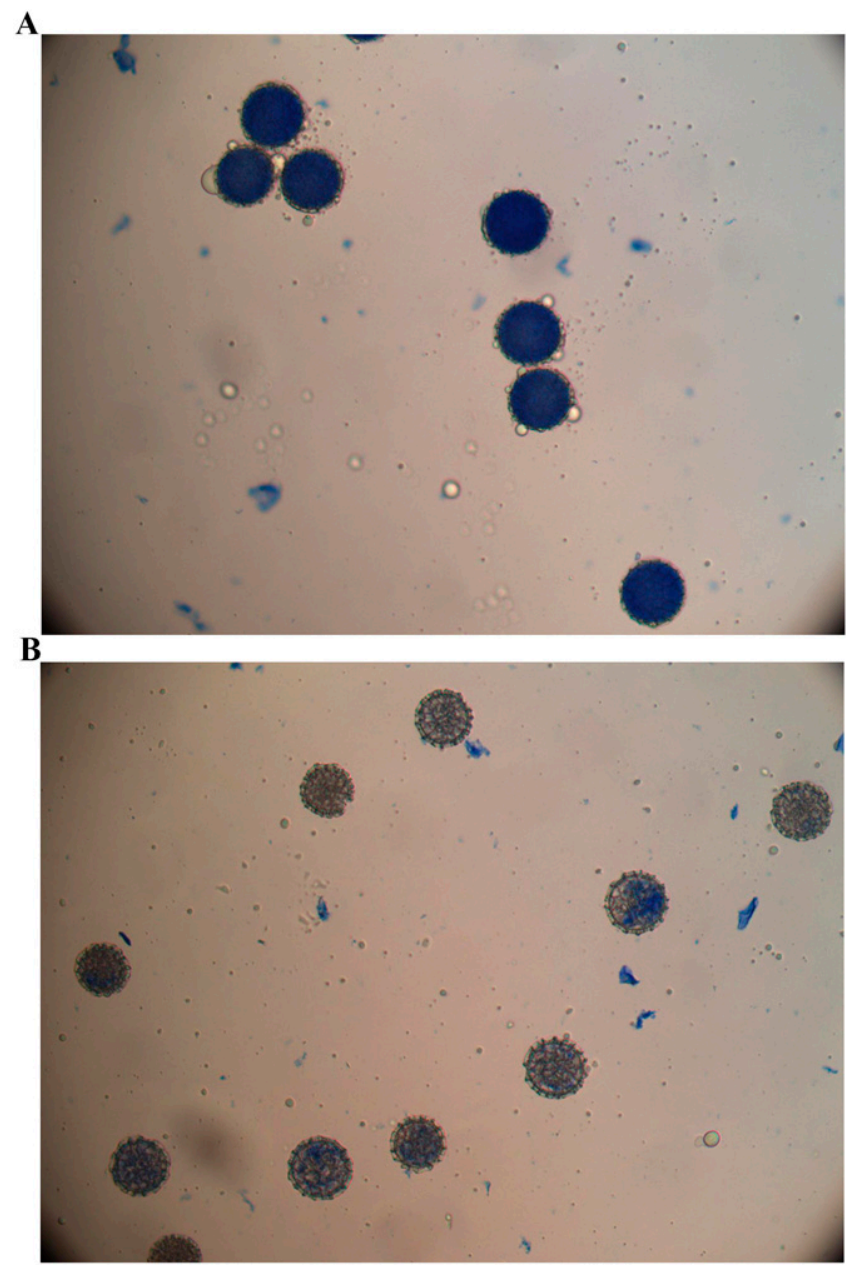

Fig. 5. (A) Staining of pollen grains of wild Ruellia simplex with lactophenol blue. (B) Staining of pollen grains of R12-1-2 with lactophenol blue. 
as described above: diploid wild $R$. simplex, diploid 'Chi Chi', and tetraploid RU64. Twenty manual hybridizations for each combination were performed. None of the cross combinations were successful in forming fruit, confirming that R12-2-1 is highly male infertile.

Pollen viability. To further confirm male sterility, pollen viability of R12-2-1 was evaluated and compared with known male fertile and male sterile clones. The viability of individual pollen grains is considered consistent with the amount of active, stainable cytoplasm. Normal, viable pollen is nearly opaque, with a rich dark blue color. Sterile, nonviable pollen is only partially stained or remains mostly unstained with a translucent, light blue color and is typically smaller in size. Stained pollen grains of smaller size and abnormally shaped grains were also considered sterile. Flowers were collected on 22 Sept. 2015 from greenhouse-grown plants at UF in Gainesville, FL, from wild $R$. simplex, 'Purple Showers', 'Chi Chi', and clone R122-1. Five flowers for each clone were collected around 9:00 AM, shortly after anthesis to ensure full anther dehiscence and minimal pollen loss. The corolla was carefully detached from each flower, and the four anthers were removed and placed in a $1.5-\mathrm{mL}$ eppendorf tube. Then $20 \mu \mathrm{L}$ of lactophenol cotton blue (Volu-Sol, VLC-030, Salt Lake City, UT) were micropipetted in each tube to stain the pollen grains for microscopy. The vials containing anthers and stain were centrifuged (Eppendorf Centrifuge 5415 D, Hamburg, Germany) at $0.8 \mathrm{rpm}$ for $30 \mathrm{~s}$. Then $20 \mu \mathrm{L}$ of stain containing pollen were micropipetted onto individual microscope slides and spread using cover slips. After 30 min to allow full intercalation of stain to cytoplasm, the slides were examined using a light stereoscope at $10 \times$ magnification (Leica DM1000; Leica Inc. Allendale, $\mathrm{NJ}$ ), and used to count a total of 25 pollen grains from each sample. A digital microscope camera (Retiga 2000R; Qimaging, Surrey, BC) with $200 \times$ magnification was used to obtain photographs of each slide (Fig. 5). Wild R. simplex and 'Chi Chi' had high pollen viability $(63 \%$ and $68 \%$, respectively), whereas 'Purple Showers' and 'R12-2-1' had low viability ( $5 \%$ and $3 \%$, respectively). Low pollen viability of R12-2-1 confirms that this clone is highly male infertile.

\section{Conclusions}

Purple-flowered clone R12-2-1 has superior landscape performance than wild $R$. simplex and purple-flowered commercial cultivars Purple Showers and Mayan Purple. It is more compact and has more branching, resulting in a fuller and more appealing appearance. Flower size and color are comparable to that of Mayan Purple, although flowering is less profuse. Furthermore, it has been demonstrated that R12-2-1 is fruitless, has very low pollen viability, and is not able to hybridize as a female or male parent with wild Ruellia or other fertile cultivars, therefore it will not pose an invasive threat by seed dispersal.

\section{Availability}

A U.S. plant patent will be applied for R12-2-1. Plants will be marketed under the name Mayan Compact Purple. Information about plant material, licensing, and propagation agreements can be obtained from the Florida Foundation Seed Producers, Inc., P.O. Box 309, Greenwood, FL 32443.

\section{Literature Cited}

American Horticultural Society. 2015. AHS Plant heat zone map. 9 Dec. 2015. <http://www.ahs. org/gardening-resources/gardening-maps/heatzone-map>.

Arumuganathan, K. and E.D. Earle. 1991. Estimation of nuclear DNA content of plants by flow cytometry.

Florida Exotic Pest Plant Council (FLEPPC). 2015. Florida Exotic Pest Plant Council's list of invasive plant species. 9 Dec. 2015. $<\mathrm{http}$ ://www.fleppc.org/list/2015FLEPPCLISTLARGEFORMAT-FINAL.pdf $>$.
Freyre, R. and S.B. Wilson. 2014. Ruellia simplex R10-105-Q54 ('Mayan Pink'). HortScience 49:499-502.

Freyre, R., A. Moseley, S.B. Wilson, and G.W. Knox. 2012a. Breeding and evaluating for fruitless Mexican petunia (Ruellia, Acanthaceae). HortScience 47:1245-1251.

Freyre, R., A. Moseley, S.B. Wilson, and G.W. Knox. 2012b. Fruitless Ruellia simplex R10102 ('Mayan Purple') and R10-108 ('Mayan White'). HortScience 47:1808-1814.

Gilman, E.F. 1999. Ruellia brittoniana, Fact Sheet FPS-513. Environmental Horticulture Department, Florida Cooperative Extension Service, Institute of Food and Agricultural Sciences, University of Florida. 9 Dec. 2015. <https:// edis.ifas.ufl.edu/fp513>.

Hupp, K.V.S., A.M. Fox, S.B. Wilson, E.L. Barnett, and R.K. Stocker. 2009. Natural area weeds: Mexican Petunia (Ruellia tweediana). ENH1155. Environmental Horticulture Department, Florida Cooperative Extension Service, Institute of Food and Agricultural Sciences, University of Florida. 9 Dec. 2015. $<$ http://edis.ifas.ufl.edu/ep415>.

IFAS Invasive Plant Working Group. 2015. IFAS Assessment of Non-Native Plants in Florida's Natural Areas. 9 Dec. 2015. <http://assessment. ifas.ufl.edu/assessments/ruellia-simplex/>.

Jones, J.R., T.G. Ranney, and T.A. Eaker. 2008. A novel method for inducing polyploidy in Rhododendron seedlings. J. Amer. Rhododendron. Soc. Summer:130-135.

Royal Horticulture Society. 1995. RHS colour chart. Royal Horticulture Society, London, UK.

SAS Institute. 2004. SAS for Windows, version 9.1.3. Cary, NC.

Tripp, E.A. 2007. Evolutionary relationships within the species-rich genus Ruellia (Acanthaceae). Syst. Bot. 3:628-649.

United States Department of Agriculture (USDA). 2012. USDA plant hardiness zone map. 9 Dec. 2015. <http://planthardiness.ars. usda.gov/PHZMWeb/>.

Wilson, S.B. and L.K. Mecca. 2003. Seed production and germination of eight cultivars and the wild type of Ruellia tweediana: A potentially invasive ornamental.

Wirth, F.F., K.J. Davis, and S.B. Wilson. 2004. Florida nursery sales and economic impacts of 14 potentially invasive ornamental plant species. J. Environ. Hort. 22:12-16. 